\title{
Subtidal Rocky Shore Communities of the Azores: Developing a Biotope Survey Method
}

\author{
Francisco F.M.M. Wallenstein ${ }^{\dagger}$, Ana I. Neto ${ }^{\dagger}$, Nuno V. Álvaro ${ }^{\dagger}$, and Ian Tittley
}

UUniversidade dos Açores

CIRN, Grupo de Ficologia, Departamento de Biologia

Rua da Mãe de Deus, 52

Apartado 1422, 9501-801 Ponta Delgada

São Miguel, Açores, Portugal

fmacedo@notes.uac.pt

\author{
*Botany Department \\ Natural History Museum \\ Cromwell Road \\ London SW7 5DB, United Kingdom
}

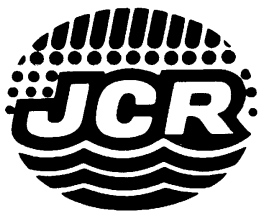

\section{ABSTRACT}

WALLENSTEIN, F.F.M.M.; NETO, A.I.; ÁLVARO, N.V., and TITTLEY, I., 2008. Subtidal rocky shore communities of the Azores: Developing a biotope survey method. Journal of Coastal Research, 24(1A), 244-249. West Palm Beach (Florida), ISSN 0749-0208.

\begin{abstract}
At 23 sites selected randomly around the island of São Miguel (Azores), video records were made at the depths of 5, $10,15,20,25$, and $30 \mathrm{~m}$ where a rocky substratum was present. Semiquantitative abundance data of the most common benthic organisms (algae and fixed/sedentary macroinvertebrates) were recorded in the vicinity of each depth reference point. Qualitative samples of the more conspicuous organisms were taken for confirmation of identification in the laboratory. At each site, substratum type, geographical orientation, and depth level were recorded. Multivariate analysis (nonmetric multidimensional scaling; analysis of similarity [Anosim] tests; similarity percentages [Simper] analysis) on the collected data enabled patterns of community distribution to be identified, as well as their relationship to abiotic factors. Since depth was found to be the sole determining factor for communities, it was the only one considered in the subtidal biotope survey protocol proposed here.
\end{abstract}

ADDITIONAL INDEX WORDS: Methodologies, rocky shores, quantification, image.

\section{INTRODUCTION}

Coastal ecosystem and community classifications for management purposes have been developed recently in the European Union and United States (CoNNOR et al., 1997; HisCOCK, 1995; Mumby and HaRborne, 1999; ZaCHARIAS and RoFF, 2000) and the marine biotope classification for Great Britain and Ireland by CONNOR et al. $(1997,2003,2004)$ is one of the most comprehensive. It is a hierarchical model that can be applied to any ecosystem and includes a larger habitat definition that coincides with the main divisions of the littoral zone. It contains subdivisions into habitat complexes and further into biotope complexes based on substrate categories and/or hydrodynamic features. These are further subdivided into biotopes according to the dominant and/or more abundant species at each location; subbiotopes are based on other noteworthy species. TITTLEY and BARTSCH (unpublished data) tested the British biotope classification on the North Sea island of Helgoland using numerical methods, and, in some cases where it proved difficult to determine biotopes precisely in the field, numerical analysis also produced unclear results. ZACHARIAS, MORRIS, and HowEs (1999) developed a model that allies the applicability of CONNOR et al. (1997) to larger scales with the possibility of predicting communities based on the physical characteristics of the habitat.

DOI:10.2112/05-0590.1 received 14 September 2005; accepted in revision 12 April 2006.
Although comprehensive, the abovementioned studies are essentially descriptive and the methodologies provided are not directly applicable to the Azores. The islands of the Azores are situated near the middle Atlantic Ocean $\left(37^{\circ} 40^{\prime} \mathrm{N}\right.$ and $25^{\circ} 31^{\prime} \mathrm{W}$ ) and are exposed to medium and high levels of wave action and have a very restricted coastal zone with a depth of $1000 \mathrm{~m}$ at $200 \mathrm{~m}$ offshore. The shores of these volcanic islands have a varying geomorphology, with cliffs alternating with rocky beaches of irregular rock sizes (BoRGES, 2004; Morton, BritTon, and MARTIns, 1998) that provide habitat for a wide variety of fauna and flora. A recent preliminary classification of Azorean marine biotopes (TITTLEY and NETO, 2000) revealed structural and functional differences between Azorean and Northern European biotopes. Methodologies and guidelines used by ZaChARIAs, Morris, and Howes (1999) and ConNor et al. (1997) are not directly applicable to the Azores because of its shore geomorphology and lack of continental shelf, with wave dynamics creating a different environment for algal communities to develop. The most striking feature in the Azores is the absence of the large canopy-forming brown algae that dominate Northern European shores in sheltered and moderately wave-exposed situations. Fucus spiralis is sporadic in the Azores, while Laminaria ochroleuca is known from deep water at only one location. Other large brown algae (Cystoseira spp., Sargassum spp.) characterise sheltered deep pools, lagoons, sublittoral fringe, and subtidal rocks but are not canopy forming like the fucoids and kelps. The sea shores of the Azores at both in- 
tertidal and sublittoral levels are mainly dominated by algal turfs, $1-3 \mathrm{~cm}$ in height, that cover the rocks as a carpet (NETO, 2001). Intertidal communities are often characterised by multispecific turfs, a feature shared with other parts of Macaronesia and West Africa. The vertically zoned communities of Gelidium microdon, Corallina elongata, Pterocladiella capillacea, Asparagopsis armata, and Codium adhaerens occur widely in the Azores (Neto 2000; Neto and TitTley, 1995; Tittley and Neto, 2000; Tittley, Neto, and FARNHAM, 1998) and create a distribution pattern intermediate between that on temperate shores where canopy-forming algae are often visually obvious and characterizing components of the biota (e.g., BARTsch and TitTlEy, 2004) and tropical shores, which are usually characterised by algal turfs and invertebrates (e.g., Foster-Smith et al., 2001; NETO, 2000).

Recent studies of biotopes and species assemblages on intertidal shores (WALLENSTEIN and NeTO, 2006) revealed varying occurrences according to substrate category, shore height, and wave exposure. The (WALLENSTEIN and NETO, 2006) study also defined a standard method for future intertidal biotope surveys in the Azores. This paper presents the results of a preliminary study on the subtidal communities of the Azores from which a protocol for future biotope surveys in the Azores is proposed. The approach presented here for the Azores is potentially applicable elsewhere in Macaronesia and possibly other biogeographical regions where turf assemblages prevail. The creation of a prescribed methodology for wider use is determined by the need for comparability of results.

\section{METHODS}

\section{Site Selection}

Rocky shore study sites around the island of São Miguel were selected randomly by overlying a $2 \mathrm{~km} \times 2 \mathrm{~km}$ grid on a map of the island. The grid intersections around the coastline created a pool of potential study sites numbered 1 to 71 . Since most intersections did not fall directly on the coastline, a study site was located by a north or south or east or west landward projection from a numbered intersection. Sampling sites were selected from the pool of 71 using random numbers. The total number of sites to be studied was not defined a priori; study ceased at the end of the summer period when sea conditions prevented further work. Altogether 23 sites were studied.

\section{Field Study}

All sites were studied by SCUBA diving to a maximum depth of $30 \mathrm{~m}$ for safety reasons (JoINER, 2001). At each site habitats where hard substrate was present were studied at reference depths of $5,10,15,20,25$, and $30 \mathrm{~m}$ along a transect and were filmed using a video camera (Sony DCR-TRV $240 \mathrm{E}$ inside an Aquatica aluminium casing). An overview was taken at each depth reference point by slowly rotating the video camera through $360^{\circ}$. Algae and macroinvertebrate species and assemblages at the reference depths were then filmed. After fieldwork, film was edited using the software iMovie 3.0.3 for Macintosh, saved in Quicktime format, and compiled in DVD format as a permanent record for checking purposes. The substratum at each study site was classified by direct observation into three categories: cobbles, boulders, and bedrock (WALLENSTEIN and NETO, 2006). The most common algae and macroinvertebrates were recorded in the vicinity of each depth reference point semiquantitatively using the DAFOR scale (D, dominant, $>75 \%$; A, abundant, 50-75\%; $\mathrm{F}$, frequent, 25-50\%; O, occasional, 5-25\%; $\mathrm{R}$, rare, $<5 \%$; Neto, 1997). Qualitative samples of the more conspicuous algae were taken for confirmation of identification in the laboratory.

\section{Data Treatment and Analysis}

Data (species and their DAFOR abundances at every depth at each study site) were analysed numerically using the Primer v. 6 software package (CLARKE and WARWICK, 2001). Nonmetric multidimensional scaling (nmMDS) was used to express the Bray Curtis similarity of depth recordings at sites based on the species present and their abundance. Results were expressed as two-dimensional plots in which the separation of sample points indicated the degree of similarity. Points in the plots were subsequently labelled with geographical, substratum and depth information to facilitate interpretation. Analysis of similarity (Anosim), a nonparametric procedure applied to the rank similarity matrix underlying the ordination of site recordings, was used to test the significance of the grouping in the nmMDS plot of sample points against abiotic factors. The similarity percentages (Simper) analysis, species contribution to similarity, was used to identify the species responsible for separating points in the plots.

\section{RESULTS AND DISCUSSION}

Sixteen biological categories were identified from the video recordings, based on the most conspicuous subtidal organisms of Azorean shores. These were ( $c f$. WALLENSTEIN and NeTo, 2006): Asparagopsis / Falkenbergia, calcareous crusts, Calcareous turf, Codium elizabethiae, Dictyota bartayrsiana, Dictyota dichotoma, Dictyota volubilis, Halopteris filicina, Jania longifurca, Peyssonnelia sp., P. capillacea, Stypocaulon scoparium, noncalcareous turf, Zonaria tournefortii, hydrozoans, and sponges.

The results of the nmMDS analysis based on the semiquantitative abundances in the above categories are given in Figures 1-3. The results for the Anosim and Simper tests are given in Tables $1-3$.

\section{Geographical Aspect}

No clear grouping was identified in the nmMDS plot when the geographical aspect of the sampling sites was overlaid (Figures $1 \mathrm{a}$ and $\mathrm{b}$ ). The most evident pattern that could be identified in Figure 1a was the greater spread of recording sites from the north $(\diamond)$, west $(\diamond)$, and southwest $(\triangle)$ sides of the island when compared with those from east $(\square)$, northeast $(\square)$, and south ( $\square$ ). This pattern was maintained when data were transformed into presence-absence (which emphasizes rare species) with neither the more conspicuous species nor the rare ones influencing the distribution of points in the plot (Figure 1b). 


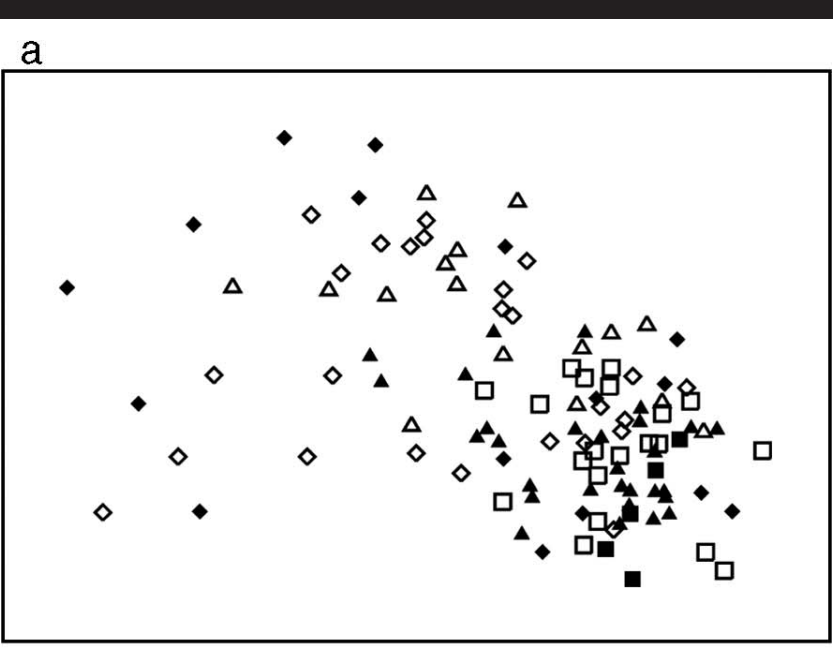

b

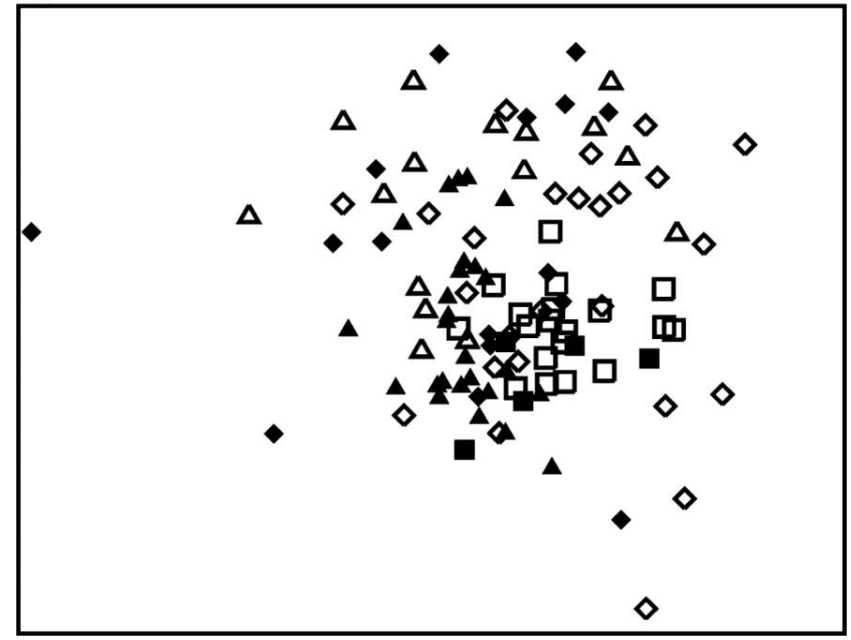

Figure 1. nmMDS plots (stress 0.17 ) with recording sites labelled by geographical aspect (a, untransformed data; b, presence-absence data; $\mathrm{S}$, $\boldsymbol{\Delta} ; \mathrm{SW}, \triangle$; E, $\square$; NE, $\square$; W, $\diamond$ N, $\diamond)$.

\section{Substrata}

Adding substratum information to the ordination showed no clear trends or grouping, and all substrata categories overlapped with each other (Figure 2). A high stress value supports this. The low number of recording sites with cobbles ( $\square$, substratum C) indicated the low abundance of this type of substratum around the island, since selection of study sites was random.

The results of the Anosim pairwise comparisons, based on random permutations, gave a global $R$ value near to zero (Table 1), which indicated no significant differences between recording sites, and thus substratum type does not have any impact in community composition. This is consistent with the nmMDS plot, which also showed no differences between substratum types.

\section{Depth}

Depth differences or a gradient in community structure were not easily identifiable from the nmMDS plot, and the

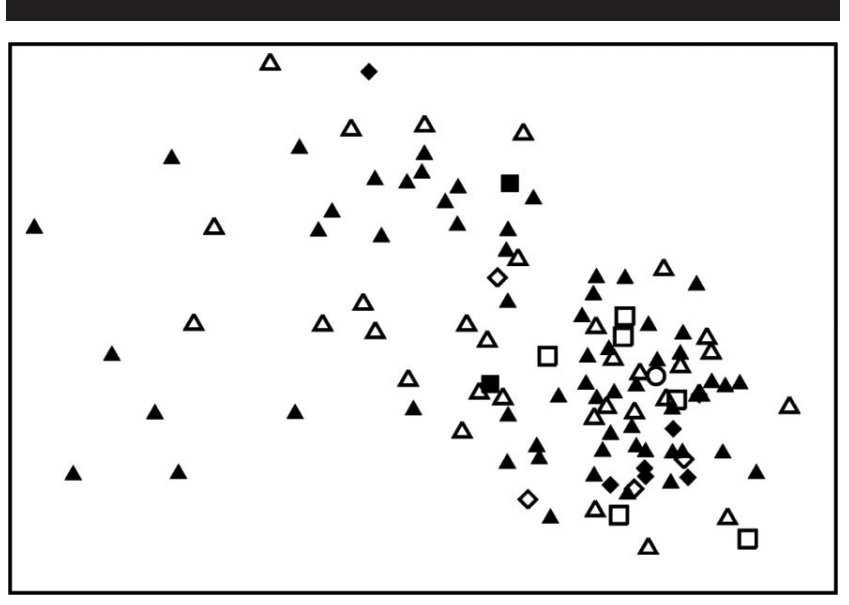

Figure 2. MDS plot (stress 0.17), for untransformed data, where sample quadrats are labelled by the substratum category where they were read (bedrock, $\mathbf{\Delta}$; boulders, $\triangle$; cobbles, $\mathbf{\square}$; boulders + bedrock, $\square$; boulders + cobbles, $\diamond$; bedrock + cobbles, o; tetrapods, $\diamond$ ).

lack of differences was confirmed by a high stress value (Figure 3). Closer inspection of the plot suggested separation of some recording sites between the shallowest $(\boldsymbol{\Lambda}, 5 \mathrm{~m})$ and deepest $(\diamond, 30 \mathrm{~m})$ levels, but intermediate levels $(\triangle, \mathbf{\square}, \square$, and $\diamond$ ) were intermingled and indicated the patchy pattern of algal communities associated with rocky substrata in the Azores.

The Anosim tests (Table 2) for significant differences between recording sites at differing depths identified significant separation between $5 \mathrm{~m}$ and below $20 \mathrm{~m}$, and between 10 and $25 \mathrm{~m}$. In contrast, the very low global $R$ value indicated no significant differences in community composition across recording sites at all depths.

The results of a one-way Simper analysis on untransformed data showed the transition of communities with increased depth (Table 3). The average similarity within depth groups was relatively low, but it was consistently higher at deeper

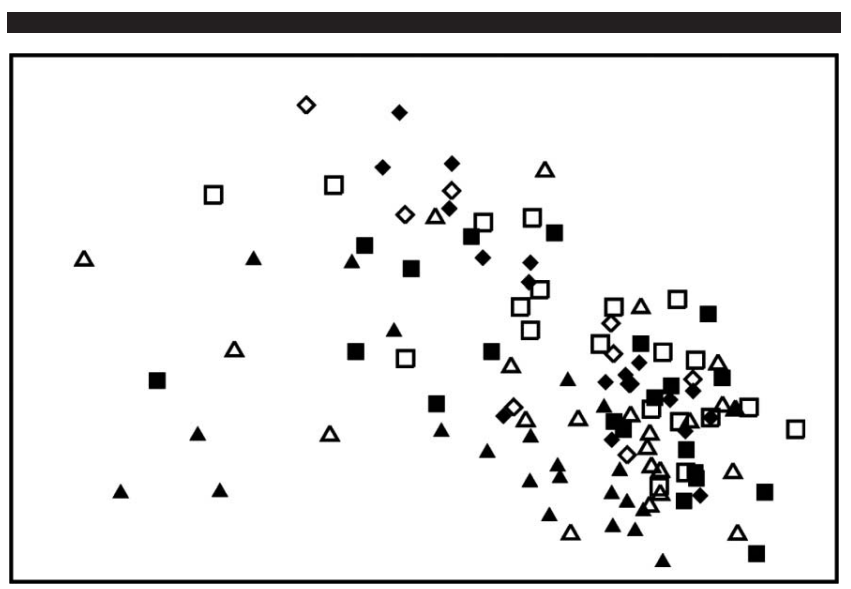

Figure 3. nmMDS plot (stress 0.17) of untransformed data with depths of recording sites $(5 \mathrm{~m}, \boldsymbol{\Delta} ; 10 \mathrm{~m}, \triangle ; 15 \mathrm{~m}, \boldsymbol{\square} ; 20 \mathrm{~m}, \square ; 25 \mathrm{~m}, \diamond ; 30 \mathrm{~m}$, $\diamond)$. 
Table 1. ANOSIM global test for substrata; sample statistic (global R), -0.035 significance level of sample statistic, 78.6\%; number of permutations, 999 (random sample from a large number); number of permuted statistics greater than or equal to global R, 785 (R, bedrock; B, boulders; $C$, cobbles; bold rows indicate a significant result).

\begin{tabular}{ccc}
\hline \hline Groups Pairwise Tests & $R$ Statistic & Significance Level \% \\
\hline R, B + R & -0.066 & 66.7 \\
R, B & 0.007 & 34.7 \\
R, B + C & -0.064 & 67.1 \\
R, T & -0.073 & 62.1 \\
R, C & 0.032 & 33.9 \\
R, R + C & -0.202 & 79 \\
B + R, B & -0.119 & 83.3 \\
B + R, B + C & 0.07 & 16.3 \\
B + R, T & -0.04 & 56.2 \\
B + R, C & $\mathbf{0 . 5 5 2}$ & 3.6 \\
B + R, R + C & -0.244 & 71.4 \\
B, B + C & -0.053 & 66.1 \\
B, T & -0.13 & 82.4 \\
B, C & -0.022 & 45.9 \\
B, R + C & -0.245 & 79.4 \\
B + C, T & 0.132 & 18.5 \\
B + C, C & $\mathbf{0 . 3 9 6}$ & 8.3 \\
B + C, R + C & 0.102 & 37.5 \\
T, C & 0.214 & 20 \\
T, R + C & -0.083 & 60 \\
C, R + C & -1 & 100 \\
\hline
\end{tabular}

levels. The results showed (1) the 5-m depth level to be mainly characterised by the exclusive presence of calcareous algal turf characteristic of the transition from the intertidal to the subtidal zones, (2) at 10-20 m the presence of Dictyota spp. as the most striking feature, and (3) at 20-30 m the occurrence of $Z$. tournefortii, characteristic of deeper levels; calcareous crusts, $H$. filicina and sponges were well distributed along the whole depth gradient.

\section{CONCLUSIONS}

Results for the geographical aspect of recording sites indicated no floristic differences on the north, south, east, and west coasts and that the entire island can be considered uniform for random selection of study sites. Results also show that there are no significant differences in algal assemblages on differing substrata, unlike at intertidal levels (WALLENSTEIN and NETO, 2006), and future studies should not take this factor into consideration. The composition of the communities derived from the Simper analysis (Table 3) based on average abundances of species at each depth level also represented a first attempt at biotope definition. This preliminary result gave an indication of the species to be used in a biotope classification.

The definition of a precise method for community characterization and consequent biotope identification is important for comparison studies in space and time. The method developed for the island of São Miguel, detailed iteratively below, is systematic and recognizes the need to collect data in a structured and systematic way, as is usual in quantitative ecological studies. Published information on algal communities in the Azores (Neto and Tittley, 1995; Tittley, Neto, and FARNHAM, 1998) indicates that the method will have
Table 2. ANOSIM global test for depth; sample statistic (global R), 0.045; significance level of sample statistic, 1.5\%; number of permutations, 999 (random sample from a large number); number of permuted statistics greater than or equal to global $\mathrm{R}, 14$ (bold rows indicate a significant result).

\begin{tabular}{ccc}
\hline \hline Groups Pairwise Tests & $R$ Statistic & Significance Level \% \\
\hline 5,10 & 0.037 & 8.6 \\
5,15 & 0.051 & 6.1 \\
$\mathbf{5 , 2 0}$ & $\mathbf{0 . 1 5 0}$ & $\mathbf{0 . 2}$ \\
$\mathbf{5 , 2 5}$ & $\mathbf{0 . 1 6 5}$ & $\mathbf{0 . 3}$ \\
$\mathbf{5 , 3 0}$ & $\mathbf{0 . 1 5 0}$ & $\mathbf{7 . 6}$ \\
10,15 & -0.013 & 62.4 \\
10,20 & 0.027 & 16.7 \\
$\mathbf{1 0}, \mathbf{2 5}$ & $\mathbf{0 . 0 6 4}$ & $\mathbf{5 . 8}$ \\
10,30 & 0.110 & 14.1 \\
15,20 & -0.031 & 87.5 \\
15,25 & -0.007 & 46.9 \\
15,30 & -0.001 & 43.6 \\
20,25 & -0.035 & 89.9 \\
20,30 & 0.001 & 40.6 \\
25,30 & -0.040 & 67.9 \\
\hline
\end{tabular}

wider application in the Azores archipelago and throughout Macaronesia.

\section{BIOTOPE SURVEY PROTOCOL}

The results of this preliminary survey and analysis suggest that future surveys should undertake stratified sampling along a depth gradient between the two extreme depth levels, 5 and $30 \mathrm{~m}$, likely to show differences in community structure. Two intermediate (transition) levels should be studied to establish whether or not recordings at these levels associate more closely with those at upper or lower levels. To reduce variation within depth levels, sampling should be restricted to 2-m depth ranges, with depth intervals of $6 \mathrm{~m}$ between (i.e., 4-6, 12-14, 20-22, and 28-30 m). Thus, the model for future biotope survey methods on São Miguel suggests that location is nested in each depth level, and six locations will be studied at each depth level, with three replicated recordings made at each location.

\section{Field Method}

(1) Six locations per depth level to be selected randomly.

(2) The first sample quadrat to be placed by chance at the middle depth level (i.e., 5, 13, 21, $29 \mathrm{~m}$ ).

(3) Subsequent quadrats to be recorded in a direction and distance from each other determined by two-digit random numbers (11 to 89 for which the second digit dictates the distance 1 to $9 \mathrm{~m}$, while the first digit dictates direction, 1, north; 2, northeast; 3 , east; 4 , southeast; 5 , south; 6 , southwest; 7 , west; 8 , northwest). Random numbers requiring sampling outside the depth range to be ignored.

(4) Percentage cover of algal species to be recorded in three replicate readings of three $0.50 \mathrm{~m} \times 0.50 \mathrm{~m}$ quadrats (nine in total, see NETO, 1997).

(5) Algae, sponges, hydrozoans, and bryozoans to be recorded quantitatively using the point-to-point method (HAwkINS and JONES, 1992). 
Table 3. SIMPER analysis results showing average abundance of species / ecological classes at each depth level, and their percentage contribution to the similarity of recording sites at each depth level for both presence-absence data (transformed data, left-hand side) and percentage cover data (untransformed data, right-hand side). Bold species/ecological classes: (i) presence/absence, average abundance > 0.55; (ii) percentage cover, percentage contribution > 9.5\%).

\begin{tabular}{|c|c|c|c|c|c|}
\hline \multicolumn{3}{|c|}{ Presence-Absence Data (transformed) } & \multicolumn{3}{|c|}{ Percentage Cover Data (untransformed) } \\
\hline Species & $\begin{array}{c}\text { Average } \\
\text { Abundance }\end{array}$ & $\%$ Contribution & Species & $\begin{array}{c}\text { Average } \\
\text { Abundance }\end{array}$ & $\%$ Contribution \\
\hline \multicolumn{6}{|l|}{ Depth Group $5 \mathrm{~m}$} \\
\hline Calareous crusts & 0.70 & 24.39 & Calcareous crusts & 2.70 & 30.36 \\
\hline Calcareous turf & 0.57 & 18.17 & Calcareous turf & 2.57 & 25.56 \\
\hline Halopteris filicina & 0.57 & 14.65 & Halopteris filicina & 1.83 & 13.61 \\
\hline Sponge & 0.57 & 14.50 & Sponge & 1.00 & 7.71 \\
\hline Hydrozoans & 0.43 & 7.74 & Dictyota dichotoma & 1.17 & 5.67 \\
\hline Dictyota dichotoma & 0.35 & 6.08 & Pterocladiella capillacea & 1.22 & 5.33 \\
\hline Pterocladiella capillacea & 0.35 & 5.14 & Hydrozoans & 0.61 & 3.16 \\
\hline Average similarity: 36.64 & & & Average similarity: 34.57 & & \\
\hline \multicolumn{6}{|l|}{ Depth Group 10 m } \\
\hline Halopteris filicina & 0.70 & 18.55 & Halopteris filicina & 2.57 & 21.70 \\
\hline Sponge & 0.65 & 17.09 & Calcareous crusts & 1.91 & 14.68 \\
\hline Calcareous crusts & 0.61 & 13.93 & Sponge & 1.26 & 11.98 \\
\hline Dictyota bartayrsiana & 0.52 & 10.25 & Dichtyota barayrsiana & 1.70 & 11.30 \\
\hline Dictyota dichotoma & 0.48 & 8.59 & Calcareous turf & 1.57 & 8.14 \\
\hline Calcareous turf & 0.39 & 5.85 & Dictyota dichotoma & 1.43 & 7.87 \\
\hline Jania longifurca & 0.35 & 4.74 & Jania longifurca & 1.09 & 4.87 \\
\hline Hydrozoans & 0.35 & 4.09 & Asparagopsis / falkenbergia & 1.00 & 3.48 \\
\hline Asparagopsis / Falkenbergia & 0.35 & 3.44 & Dictyota volubilis & 0.91 & 2.87 \\
\hline Dictyota volubilis & 0.30 & 3.01 & Stypocaulon scoparium & 0.91 & 2.43 \\
\hline Zonaria tournefortii & 0.26 & 2.31 & Zonaria tournefortii & 0.83 & 2.28 \\
\hline Average similarity: 36.61 & & & Average similarity: 32.61 & & \\
\hline \multicolumn{6}{|l|}{ Depth group $15 \mathrm{~m}$} \\
\hline Calcareous crusts & 0.67 & 19.77 & Halopteris filicina & 2.57 & 23.86 \\
\hline Halopteris filicina & 0.67 & 19.71 & Calcareous crusts & 2.29 & 21.64 \\
\hline Sponge & 0.57 & 12.30 & Dictyota dichotoma & 1.81 & 13.12 \\
\hline Dictyota dichotoma & 0.52 & 11.58 & Sponge & 1.14 & 7.91 \\
\hline Hydrozonas & 0.48 & 9.00 & Hydrozoans & 0.95 & 6.66 \\
\hline Zonaria tournefortii & 0.38 & 5.27 & Zonaria tournefortii & 1.38 & 6.10 \\
\hline Dictyota bartayrsiana & 0.33 & 4.05 & Dictyota volubilis & 1.05 & 4.21 \\
\hline Dictyota volubilis & 0.29 & 3.44 & Jania longifurca & 0.95 & 2.73 \\
\hline Pterocladiella capillacea & 0.29 & 2.94 & Dictyota bartayrsiana & 0.81 & 2.48 \\
\hline Codium elizabethiae & 0.29 & 2.47 & Pterocladiella capillacea & 0.86 & 2.41 \\
\hline Average similarity: 36.55 & & & Average similarity: 32.79 & & \\
\hline \multicolumn{6}{|l|}{ Depth Group 20 m } \\
\hline Halopteris filicina & 0.90 & 32.48 & Halopteris filicina & 3.55 & 37.56 \\
\hline Dictyota dichotoma & 0.60 & 12.52 & Zonaria tournefortii & 2.20 & 13.12 \\
\hline Zonaria tournefortii & 0.60 & 11.33 & Dictyota dichotoma & 1.85 & 11.77 \\
\hline Calcareous crusts & 0.55 & 9.77 & Calcareous crusts & 1.70 & 9.57 \\
\hline Sponge & 0.50 & 7.71 & Thick turf & 1.50 & 5.90 \\
\hline Hydrozoans & 0.50 & 7.40 & Sponge & 1.00 & 5.11 \\
\hline Dictyota bartayrsiana & 0.40 & 5.19 & Hydrozoans & 0.95 & 4.89 \\
\hline Thick turf & 0.35 & 4.65 & Dictyota bartayrsiana & 1.05 & 4.04 \\
\hline Average similarity: 42.83 & & & Average similarity: 39.38 & & \\
\hline \multicolumn{6}{|l|}{ Depth group $25 \mathrm{~m}$} \\
\hline Zonaria tournefortii & 0.72 & 22.49 & Zonaria tournefortii & 2.94 & 28.55 \\
\hline Halopteris filicina & 0.72 & 20.80 & Halopteris filicina & 2.78 & 24.28 \\
\hline Sponge & 0.61 & 13.34 & Calcareous crusts & 2.00 & 12.52 \\
\hline Calcareous crusts & 0.61 & 12.40 & Sponge & 1.17 & 7.76 \\
\hline Hydrozoans & 0.44 & 6.40 & Thick turf & 1.39 & 5.65 \\
\hline Peyssonnelia sp. & 0.39 & 5.54 & Dictyota dichotoma & 1.39 & 5.28 \\
\hline Dictyota dichotoma & 0.39 & 5.16 & Peyssonnelia sp. & 1.06 & 4.01 \\
\hline Thick turf & 0.33 & 4.72 & Hydrozoans & 0.78 & 3.61 \\
\hline Average similarity: 41.98 & & & Average similarity: 39.15 & & \\
\hline \multicolumn{6}{|l|}{ Depth Group 30 m } \\
\hline Zonaria tournefortii & 0.89 & 37.32 & Zonaria tournefortii & 3.67 & 47.22 \\
\hline Calcareous crusts & 0.67 & 16.38 & Calcareous crusts & 2.22 & 15.44 \\
\hline Halopteris filicina & 0.56 & 14.29 & Halopteris filicina & 2.00 & 14.01 \\
\hline Sponge & 0.56 & 11.76 & Sponge & 1.00 & 6.52 \\
\hline Hydrozoans & 0.44 & 7.19 & Hydrozoans & 0.89 & 4.60 \\
\hline Dictyota dicthotoma & 0.33 & 3.99 & Thick turf & 1.44 & 4.55 \\
\hline Average similarity: 42.73 & & & Average similarity: 40.68 & & \\
\hline
\end{tabular}


(6) The number of point intersections at which each species occurs to be counted (maximum of 36 ).

(7) Voucher specimens to be taken for confirmation of identification in the laboratory.

(8) Macroinvertebrate recording (sea urchins, sea stars, sea cucumbers, tube worms, and fire worms) to be undertaken within a minimal sampling area of $1.5 \mathrm{~m} \times 15 \mathrm{~m}$ replicated three times (see MARTINs et al., 2005) in which the groups of organisms above are counted.

\section{Data Treatment}

(1) Percentage cover of benthic organisms to be entered into a spreadsheet for each sample area.

(2) Data imported to the software Primer v. 6.

(3) MDS analysis to be used to identify grouping of samples according to different abiotic factors.

(4) Anosim to be used to test the significance of groups identified.

(5) Simper analysis to identify the species that contribute to the separation of samples according to factor, and to suggest a preliminary biotope classification, for both transformed data (presence-absence) and untransformed data.

(6) Species relevant for biotope definition to be chosen according to both following criteria:

a. Average abundance $>0.55$ (for presence-absence data).

b. Percentage contribution $>9.5 \%$ (for untransformed data).

\section{ACKNOWLEDGMENTS}

The authors wish to thank Dr. Kenneth Robert Clarke of the Plymouth Marine Laboratory for helping with the data treatment and interpretation, the firm NERUS for supplying a boat, skipper, and some SCUBA gear when necessary, and João Brum and Pedro Raposeiro for helping with field work. We also thank the anonymous referees who helped improve the manuscript. This work was funded by the project POCTIMGS/54319/2002, Biotope, Classification, Mapping, and Modelling of Azores Littoral Biotopes, and supported also by CIRN-Centro de Investigação de Recursos Naturais, both from Fundação para a Ciência e Tecnologia (Portugal). The work performed in the present study complies with the current laws of Portugal.

\section{LITERATURE CITED}

Bartsch, I. and Tittley I., 2004. The rocky intertidal biotopes of Helgoland: Present and past. Helgoland Marine Research, 58, 289302.

Borges, P., 2004. Ambientes litorais nos grupos Central e Oriental do arquipélago dos Açores, conteúdos e dinâmica de microescala. Ponta Delgada, Portugal: Universidade dos Açores, Ph.D. thesis, 413p.

Clarke, K.R. and WarwiCK, R.M., 2001. Change in Marine Communities: An Approach to Statistical Analysis and Interpretation (2nd edition). Plymouth, UK: PRIMER-E, 176p.

Connor, D.W.; Allen, J.H.; Golding, N.; Howell, K.L.; LieberKNeCHT, L.M.; Northen, K.O., and ReKer J.B., 2004. The Ma- rine Habitat Classification for Britain and Ireland (version 04.05). Peterborough, UK: Joint Nature Conservation Committee. www.jncc.gov.uk/MarineHabitatClassification (accessed May 6, 2006).

Connor, D.W.; Allen, J.H.; Golding, N.; Lieberknecht, L.M.; Northen, K.O., and ReKer, J.B., 2003. The National Marine Habitat Classification for Britain and Ireland (version 03.02). Peterborough, UK: Joint Nature Conservation Committee. www.jncc.gov.uk/marinehabitatclassification (accessed November 4, 2003).

Connor, D.; Brazier, D.P.; Hill, T.O., and Northen, K.O., 1997. Marine Nature Conservation Review: Marine Biotope Classification for Britain and Ireland, Volume 1. Littoral biotopes (version 97.06). Peterborough, UK: Joint Nature Conservation Committee, Report no. 229, 361p.

Foster-Smith, B.; Antia, E.; Kendall, M.; John, D., and Seku, F., 2001. Shore biotopes of West Africa-An introduction to biotope mapping. University of Newcastle, Institute of Oceanography-University of Calabar, The Natural History Museum, University of Ghana, Plymouth Marine Laboratory, Darwin Initiative Report 3, Ref. 162/7/451.

Hawkins, S.J. and Jones, H.D., 1992. Marine Field Course Guide. 1. Rocky Shores. Marine Conservation Society. London, UK: Immel Publications, $144 \mathrm{p}$.

Hiscock, K. (ed.), 1995. Classification of benthic marine biotopes of the north-east Atlantic. In: Proceedings of a BioMar-Life Workshop (Cambridge, UK; 16-18 November 1994). Peterborough, Joint Nature Conservation Committee.

JoIner, J.T. (ed.), 2001. NOAA Diving Manual, Diving for Science and Technology (fourth edition). Flagstaff: Best Publishing Company, 660p.

Martins, G.M.; Wallenstein F.F.M.; Álvaro, N.V.; Neto, A.I. and Costa, A.C., 2005. Sampling strategies for biotope definition: Minimal sampling area for selected groups of macroinvertebrates in the rocky subtidal of São Miguel, Azores. Helgoland Marine Research, 59, 219-223.

Morton, B.; Britton, J.C., and Martins, A.M.F., 1998. Coastal Ecology of the Azores. Ponta Delgada, Portugal: Sociedade Afonso Chaves, 249p.

Mumby, P.J. and Harborne, A.R., 1999. Development of a systematic classification scheme of marine habitats to facilitate regional management and mapping of Caribbean coral reefs. Biological Conservation, 88, 155-163.

Neto, A.I., 1997. Studies on algal communities of São Miguel, Azores. Ponta Delgada, Portugal: Universidade dos Açores, Ph.D. thesis, $\mathrm{x}+309 \mathrm{p}$.

Neto, A.I., 2000. Ecology and dynamics of two intertidal algal communities on the littoral of the Island of São Miguel (Azores). Hy drobiologia, 432, 135-147.

Neto, A.I., 2001. Macroalgal species diversity and biomass of subtidal communities of São Miguel (Azores). Helgoland Marine Research, 55, 101-111.

Neto, A.I. and TitTley, I., 1995. Structure and Zonation of algal turf communities on the Azores: A numerical approach. Boletim do Museu Municipal do Funchal, Sup. 4, 487-504.

Tittley, I. and Neto, A.I., 2000. A provisional classification of algal characterized rocky shore biotopes in the Azores. Hydrobiologia. 440(1), 19-25.

Tittley, I.; Neto, A.I., and Farnham, W.F., 1998. Marine algae of the island of Flores, Azores: Ecology and floristics. Boletim do Museu Municipal do Funchal, Sup. 5, 463-479.

WALLENSTEIN, F.F.M.M. and NETO A.I., 2006. Intertidal rocky shore biotopes of the Azores: A quantitative approach. Helgoland Marine Research, 60, 196-206.

ZACHARIAS, M.A. and RoFF, J.C., 2000. A hierarchical ecological approach to conserving marine biodiversity. Conservation Biology, 14(5), 1327-1334

Zacharias, M.A.; Morris, M.C., and Howes, D.E., 1999. Large scale characterisation of intertidal communities using a predictive model. Journal of Experimental Marine Biology and Ecology, 239, 223-242. 